\title{
HUBUNGAN ANTARA KARAMBA JARING APUNG DENGAN JENIS MAKANAN YANG TERDAPAT PADA LAMBUNG IKAN ENDEMIK DI WADUK KOTO PANJANG, RIAU
}

\author{
Eni Sumiarsih ${ }^{1}$, Otong Suhara Djunaedi', Yayat Dhahiyat ${ }^{2}$ dan $^{2}$ Zahidah ${ }^{2}$ \\ ${ }^{1}$ Universitas Riau, ${ }^{2}$ Universitas Padjadjaran \\ email korespondensi: senisaf@yahoo.co.id
}

\begin{abstract}
In the Koto Panjang Dam, Riau there are more than 1582fish floating cages present. Fish feed spilled from the cage is believed to affect the diet of wild endemic fishes inhabit the dam. To understand the effect of the cage on the diet of the endemic, a study has been conducted on May to September 2013. There were 5 sampling sites, 2 sites located in the natural area that there is no cage (St $1 \mathrm{Na}$ and St $2 \mathrm{Na}$ ) and the others ( $3 \mathrm{Ka}, 4 \mathrm{Ka}$ and $5 \mathrm{Ka}$ ) were in the area around the cage. Fishes were sampled hourly, for $a 24$ hour period and their stomach content was analyzed. Results shown that there were 31 species of endemic fishes such as Puntius schwanenfeldii, Macrones nemurus, Hampala bimaculata, Osteochillus hasselti, Rasbora vaillanti, Tynnichtys vaillanti, Ophiocephalus melanosoma, Chela oxygastroides, Cyclocheilichthys heteronema, Notopterus chilata, Puntius bramoidesandCyclocheilichtys apogon. Among these fishes, however, only P. schwanenfeldii that greatly affected by the presence of the aquaculture activities as the stomach of fish living around the cage was filled with fish feed pellets (more than $90 \%)$. The fish living in the area with no cage, however, filled with animal and plant remains. This fact indicates that the $P$. schwanenfeldii is an opportunist fish that is able to change their diet into fish feed pellets. Based on data obtained, it can be concluded that the presence of fish floating cage aquaculture activities affect certain fish species only.
\end{abstract}

Key words: Fish floating cage, Puntius schwanenfeldii, Koto Panjang Dam, endemic fish, fish feed pellet

\section{PENDAHULUAN}

Waduk Koto Panjang adalah merupakan salah satu waduk yang dibangun dengan membendung aliran Sungai Kampar Kanan dan Batang Mahat yang memiliki genangan seluas 12.400 ha. Secara geografis letak Waduk Koto Panjang adalah terletak pada posisi 0017'29" Lintang Utara (LU) dan 100043'53" Bujur Timur (BT). Sedangkan secara administratif Waduk Koto Panjang termasuk kedalam wilayah Kecamatan XIII Koto Panjang dan Bangkinang Barat Kabupaten Kampar Provinsi Riau serta Kecamatan Pangkalan Koto Kabupaten Limbah Puluh Koto Provinsi Sumatera Barat. FungsiutamaWaduk Koto Panjang adalahsebagai Pusat Pembangkit Lisrik Tenaga Air (PLTA), selainituwaduk ini digunakan sebagai tempat untuk menangkap ikan dan membudidayakan ikan dalam karamba jaring apung (KJA) serta waduk ini juga merupakan daerah objek wisata.

Kegiatan budidaya ikan di dalam karamba jaring apung di Waduk Koto Panjang semakin meningkat. Sistem pemberian pakan yang digunakan oleh petani budidaya adalah menggunakan teknologi semi intensif dengan pemberian pakan secara terus menerus sehingga ikan budidaya dapat tumbuh dengan cepat. Namun demikian tidak semua pakan yang diberikan dimakan oleh ikan dalam karamba, tetapi ada yang terbuang dan menyebar di sekitar perairan. Adanya sisa pakan yang terbuang dan menyebar ke dalam perairan ini dapat menarik ikan endemik untuk datang di sekitar karamba.

Adanya sisa pakan yang terbuang ke perairan merupakan atraktan (daya tarik) bagi ikan yang berada di sekitar karamba. Karena aroma dari pakan akan menarik ikan-ikan untuk datang mendekat di sekitar karamba. Hal ini terbukti dari hasil penelitian Sumiarsih dan Windarti (2009) yang menyatakan bahwa ikan-ikan yang hidup di sekitar karamba dapat memanfaatkan sisa-sisa pakan yang keluar dari karamba sebagai makanan utamanya. Selain itu Valle et al (2006) menyatakan bahwa keberadaan karamba dapat mempengaruhi jumlah ikan dan keanekaragaman ikan di sekitar karamba, jumlahnya lebih besar dibandingkan di area yang jauh dari karamba.

Hasil dari penelitian tentang hubungan antara keberadaan karamba dengan keberadaan ikan di Waduk Koto Panjang menunjukkan bahwa keberadaan karamba menarik ikan endemik untuk datang dan mendekat. Pada penelitian ini dijumpai ikan-ikan yang berada di sekitar karambasebanyak 31 jenis dan 11 famili. Di Waduk Koto Panjang dijumpai berbagai jenis ikan endemik, seperti ikan kapiek (Puntius schwanenfeldii), baung (Macrones nemurus), barau (Hampala bimaculata), paweh (Osteochillus hasselti) dan lain-lain. Diantara ikan-ikan tersebut yang paling banyak di jumpai adalah ikan kapiek, sedangkan ikan pantau (Rasbora vaillanti), motan (Tynnichtys vaillanti), toman (Ophiocephalus melanosoma), sepimping (Chela oxygastroides), mansai (Cyclocheilichthys heteronema) dan belida (Notopterus chilata) jarang ditemukan. Untuk melihat apakah keberadaan ikan-ikan endemik di sekitar karamba berkaitan dengan keberadaan sisa makanan berupa pelet yang berasal dari kegiatan budidaya karamba, maka penelitian ini dilakukan untuk melihat jenis-jenis makanan yang terdapat pada lambung ikan endemik di Waduk Koto Panjang, di area di mana ada karamba dan tidak ada karamba.

\section{METODE}

Metode yang digunakan dalam penelitian ini adalah metode survei, yaitu waduk Koto Panjang dan Sungai Kampar dijadikan lokasi pengambilan sampel ikan untuk penelitian analisis isi lambung ikan endemik .

\section{Penentuan stasiun}

Lokasi penelitian ditetapkan berdasarkan distribusi penyebaran KJA dan kepadatan KJA di waduk Koto - 
panjang. Dimana stasiun $1 \mathrm{Na}$ merupakan perairan sungai Kampar di mana tidak terdapat karamba, stasiun 2Na di waduk Koto Panjang, tidak terdapat karamba, sedangkan stasiun $3 \mathrm{Ka}$, 4Ka dan $5 \mathrm{Ka}$ merupakan daerah Waduk Koto Panjangyang terdapat karamba.

\section{Teknik Pengumpulan Data}

Data sampel ikan dikumpulkan melalui observasi langsung ke lapangan sesuai dengan stasiun yang telah ditetapkan dan tahapan penelitian.Pengambilan sampel ikan dan pengamatan isi lambung ikan, dilakukan dengan cara menangkap ikan sampel langsung dari lima stasiun penelitian yang telah ditetapkan. Alat tangkap yang akan digunakan berupa gill net dengan ukuran $150 \times 4 \mathrm{~m}$; (mesh size 4 inch) dan gill net dengan ukuran $100 \times 3 \mathrm{~m}$ (mesh size 3 inch).

Untuk pengamatan jenis makanan dalam lambung ikan, cara penangkapan ikan yang dilakukan adalah penangkapan ikan berturut-turut setiap 3 jam sekali dengan selang waktu 3 hari. Setiap hari penangkapan ikan dilakukan pada jam yang berbeda, sehingga data dari 3 hari penangkapan tersebut dapat mewakili data penangkapan setiap jam. Untuk lebih jelasnya jadwal penangkapan ikan dijelaskan pada Tabel 1.

Tabel 1. Jadwal Penangkapan lkan

di Waduk PLTA Koto Panjang untuk Pengamatan jenis-jenis makanan dalam lambung ikan

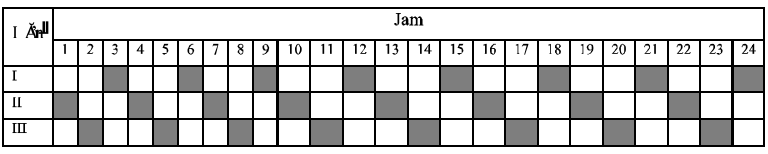

Untuk pengamatan kepenuhan isi lambung ikan, langkah yang dilakukan adalah sebagai berikut:

1. Isi lambung yang sudah diawetkan dengan formalin diambil, dicuci dengan air mengalir untuk menghilangkan formalin.

2. Kepenuhan isi saluran pencernaan diamati dan dibagi menjadi 10 kriteria yaitu:

\begin{tabular}{|c|c|c|c|}
\hline Kategori & Skor & Keterangan & DÄ \\
\hline 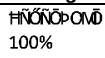 & 10 & $\begin{array}{l}\text { Lambung nampak menggembung, } \\
\text { penuh berisi makanan }\end{array}$ & \\
\hline $\begin{array}{l}\text { HÑ̄̄ōN̄ōpOn̄̄ } \\
90 \%\end{array}$ & 9 & $\begin{array}{l}\text { Lambung berisi90\% (makanan } \\
\text { memenuhi } 90 \% \text { isi lambung) }\end{array}$ & \\
\hline $\begin{array}{l}\text { HÑ̄̄óñōpOn̄̄ } \\
80 \%\end{array}$ & 8 & $\begin{array}{l}\text { Lambung berisi } 80 \% \text { (makanan } \\
\text { memenuhi } 80 \% \text { isi lambung) }\end{array}$ & \\
\hline 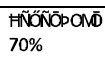 & 7 & $\begin{array}{l}\text { Lambung berisi 70\% (makanan } \\
\text { memenuhi } 70 \% \text { isi lambung ) }\end{array}$ & \\
\hline $\begin{array}{l}\text { Fĩ̄ó̄̄ōpon̄̄ } \\
60 \%\end{array}$ & 6 & $\begin{array}{l}\text { Lambung berisi } 60 \% \text { (makanan } \\
\text { memenuhi } 60 \% \text { isi lambung) }\end{array}$ & \\
\hline 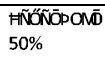 & 5 & $\begin{array}{l}\text { Lambung berisi 50\% (makanan } \\
\text { memenuhi 50\%isi lambung) }\end{array}$ & \\
\hline 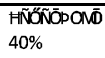 & 4 & $\begin{array}{l}\text { Lambung berisi } \mathbf{4 0 \%} \text { (makanan } \\
\text { memenuhi } \mathbf{4 0 \% i s i ~ l a m b u n g ) ~}\end{array}$ & \\
\hline 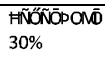 & 3 & $\begin{array}{l}\text { Lambung berisi 30\% (makanan } \\
\text { memenuhi 30\%isi lambung) }\end{array}$ & \\
\hline $\begin{array}{l}\text { HÑ̄́ŌN̄̄̄pOn̄̄ } \\
20 \%\end{array}$ & 2 & $\begin{array}{l}\text { Lambung berisi } 20 \% \text { (makanan } \\
\text { memenuhi } 20 \% \text { isi lambung) }\end{array}$ & \\
\hline 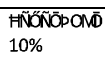 & 1 & $\begin{array}{l}\text { Lambung berisi } 10 \% \text { (makanan } \\
\text { memenuhi } 10 \% \text { isi lambung) }\end{array}$ & \\
\hline
\end{tabular}

3. Data kepenuhan isi lambung ini selanjutnya ditabulasikan dan dianalisis secara deskriptif untuk menentukan jenis makanan yang terdapat di lambungikan.

\section{HASIL DAN PEMBAHASAN}

Di sekitar karamba terdapat berbagai jenis ikan, baik ikan endemik maupun ikan non endemik. Ikan endemik adalah ikan liar atau ikan asli daerah yang tertangkap di sekitar KJA Waduk Koto Panjang, seperti ikan kapiek (Puntius schwanenfeldii), baung (Macrones nemurus), barau (Hampala bimaculata), paweh (Osteochillus hasselti), Ingir-ingir (Macrones nigriceps), julung-julung (Strongylura strongylura), bujuk (Channa lucius), toman (Ophiocephalus melanosoma), gabus (Channa sp), barau (Hampala bimaculata), motan (Tynnichtys vaillanti), pantau (Rasbora vaillanti), sepimping (Chela oxygastroides), tabingalan (Puntius bramoides), sipaku (Cyclocheilichtys apogon), pulaubuja (Osteochillus kahajenensis), mansai (Cyclocheilichthys heteronema), mali (Labiobarbus festifus), motan (Thynnichtys vaillanti), lelan (Osteochilus pleurotaenia), Selimang (Crossocheilus sp), Seluang (Rasbora sp), sunau (Puntius binotatus) dan lain-lain. Sedangkan ikan non endemik adalah ikan budidaya yang diperkirakan lepas dari karamba dan ikan introduksi, seperti ikan mas (Cyprinus carpio), gurami (Osphronemus goramy) dan ikan nila (Oreochromis niloticus) (Tabel 2).

Tabel 2. Ikan Endemik dan Non Endemik yang Terdapat di Lokasi Penelitian

\begin{tabular}{|c|c|c|c|c|c|}
\hline \multirow[b]{2}{*}{ Í ö } & \multirow[b]{2}{*}{ Famili } & \multirow{2}{*}{$\begin{array}{l}\text { Nama } \\
\text { daerah }\end{array}$} & \multirow[b]{2}{*}{ Nama Latin } & \multicolumn{2}{|c|}{ Kategori } \\
\hline & & & & $\begin{array}{c}\text { Ikan } \\
\text { endemik }\end{array}$ & $\begin{array}{l}\text { Ikan Non } \\
\text { endemik }\end{array}$ \\
\hline \multirow{2}{*}{1} & \multirow[t]{2}{*}{ Bagridae } & Baung & Macrones nemurus & $v$ & \\
\hline & & Ingir-ingir & Macrones nigriceps & $v$ & \\
\hline 2 & Belonidae & $\begin{array}{l}\text { Julung- } \\
\text { julung }\end{array}$ & Strongylura strongylura & $v$ & \\
\hline \multirow{3}{*}{3} & \multirow{3}{*}{ Channidae } & Bujuk & Channa lucius & $v$ & \\
\hline & & Toman & Ophiocephalus melanosoma & v & \\
\hline & & Gabus & Channa sp & $\mathrm{v}$ & \\
\hline 4 & Cichlidae & Nila & Oreochromis niloticus & & $\mathrm{v}$ \\
\hline \multirow{17}{*}{5} & \multirow{17}{*}{ Cyprinidae } & Barau & Hampala bimaculata & $v$ & \\
\hline & & Kapiek & Puntius schwanenfeldii & $\mathrm{v}$ & \\
\hline & & Motan & Tynnichtys vaillanti & 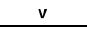 & \\
\hline & & Pantau & Rasbora vaillanti & $v$ & \\
\hline & & Sepimping & \begin{tabular}{|l} 
Chela oxygastroides \\
\end{tabular} & $\mathrm{v}$ & \\
\hline & & \begin{tabular}{|l|} 
Tabin \\
Galan \\
\end{tabular} & Puntius bramoides & $v$ & \\
\hline & & Paweh & Osteochillus hasselti & 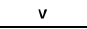 & \\
\hline & & Sipaku & Cyclocheilichtys apogon & $v$ & \\
\hline & & \begin{tabular}{|l|} 
Pulau \\
Buja
\end{tabular} & Osteochillus kahajenensis & $v$ & \\
\hline & & Mansai & Cyclocheilichthys heteronema & $v$ & \\
\hline & & Mali & Labiobarbus festifus & $\mathrm{v}$ & \\
\hline & & Mas & Cyprinus carpio & & $\mathrm{v}$ \\
\hline & & Motan & Thynnichtys vaillanti & $v$ & \\
\hline & & Lelan & Osteochilus pleurotaenia & $\mathrm{v}$ & \\
\hline & & Selimang & Crossocheilus $s p$ & $\mathbf{v}$ & \\
\hline & & Seluang & Rasbora $s p$ & $v$ & \\
\hline & & Sunau & Puntius binotatus & $\mathrm{v}$ & \\
\hline 6 & Helostomatidae & Tambakan & Helostoma temminckii & 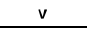 & \\
\hline 7 & Mastacembelidae & Tilan & Mastacembelus unicolor & v & \\
\hline 8 & Notopteridae & Belida & Notopterus chilata & $\mathrm{v}$ & \\
\hline \multirow[t]{2}{*}{9} & \multirow[t]{2}{*}{ Osphronemidae } & Sepat & Trichogaster trichopterus & $v$ & \\
\hline & & Gurami & Osphronemus goramy & & $v$ \\
\hline 10 & Pristolepididae & Katung & Pristolepis grotii & $v$ & \\
\hline 11 & Tetraodontidae & Buntal & Tetraodon leiurus & $v$ & \\
\hline
\end{tabular}

Berdasarkan analisis isi lambung ikan endemik di Waduk Koto Panjang dan perairan Sungai Kampar menunjukkan bahwa terdapat perbedaan jenis makanan pada ikan endemik yang terdapat di daerah 
yang jauh dari karamba (stasiun $1 \mathrm{Na}$ dan $2 \mathrm{Na}$ ) dengan daerah dekat karamba (stasiun $3 \mathrm{Ka}$, $4 \mathrm{Ka}$ dan $5 \mathrm{Ka}$ ). Jenis makanan yang terdapat di lambung ikan endemik di Waduk Koto Panjang di area sekitar karamba adalah plankton, debris, lumut, sisa organisme, sisa tumbuhan dan pelet, sedangkan jenis makanan di lambung ikan yang jauh dari karamba tidak terdapat pelet.

Jenis-jenis makanan pada masing-masing ikan berbeda-beda. Pada stasiun $1 \mathrm{Na}$ dan $2 \mathrm{Na}$, yaitu lingkungan natural di mana tidak ada karamba, jenis makanan ikan bervariasi. Pada ikan barau jenis makanannyaterdiri dari sisa organisme (4-70 \%) dan debris (4,4\%). Pada ikan kapiek makanannya terutama adalah debris $(96,2-96,7 \%)$ dan plankton (3,3-8\%). jenis makanan ikan katung terutama terdiri dari sisa tumbuhan $(54,4 \%)$, sisa organisme $(33,3 \%)$ dan lumut $(10,9 \%)$, jenis makanan ikan sipaku sisa tumbuhan $(62,6 \%)$, sisa organisme $(13,9 \%)$, lumut $(2,6 \%)$ dan debris $(18,4 \%)$, jenis makanan ikan baung terdiri dari sisa organisme $(75 \%)$ dan sisa tumbuhan $(25 \%)$.

Di antara jenis-jenis ikan tersebut, antara ikan yang hidup di area karamba dan di area natural, hanya ikan kapiek yang isi lambungnya berbeda. Pada ikan kapiek yang hidup di area natural, isi lambungnya didominasi oleh debris, sedangkan pada ikan kapiek yang hidup di sekitar karamba, isi lambungnya didominasi oleh pelet ikan. Sedangkan ikan lain, isi lambungnya tidak begitu berbeda. Hal ini menunjukkan bahwa di antara ikanikan yang tertangkap selama penelitian, hanya ikan kapiek yang merupakan ikan yang bersifat oportunis. Menurut Wikipedia (2013) ikan oportunis adalah ikan yang mengambil kesempatan untuk memanfaatkan makanan kapanpun makanan itu tersedia. Selain itu ikan oportunis tersebut mampu merubah tingkah laku mencari makan (foraging behavior) sesuai dengan ketersediaan makanan di mana ikan tersebut hidup (Anonim, 2013).

Pada ikan kapiek, komposisi isi lambung benarbenar menunjukkan bahwa ikan tersebut adalah ikan oportunis. Di area di mana tidak ada sisa pelet ikan, ikan kapiek hanya makan debris. Tetapi di area di mana tersedia sisa pelet ikan, ikan kapiek makan pelet saja, bahkan lebih dari $90 \%$ isi lambung ikan tersebut adalah pelet. Hal ini menunjukkan bahwa ikan kapiek mampu memanfaatkan sisa pelet yang tersedia di perairan dan merubah tingkah laku makannya sehingga menjadi ikan pemakan pelet. Fakta tersebut di atas mengindikasikan bahwa keberadaan karamba dapat merubah pola makan ikan kapiek.
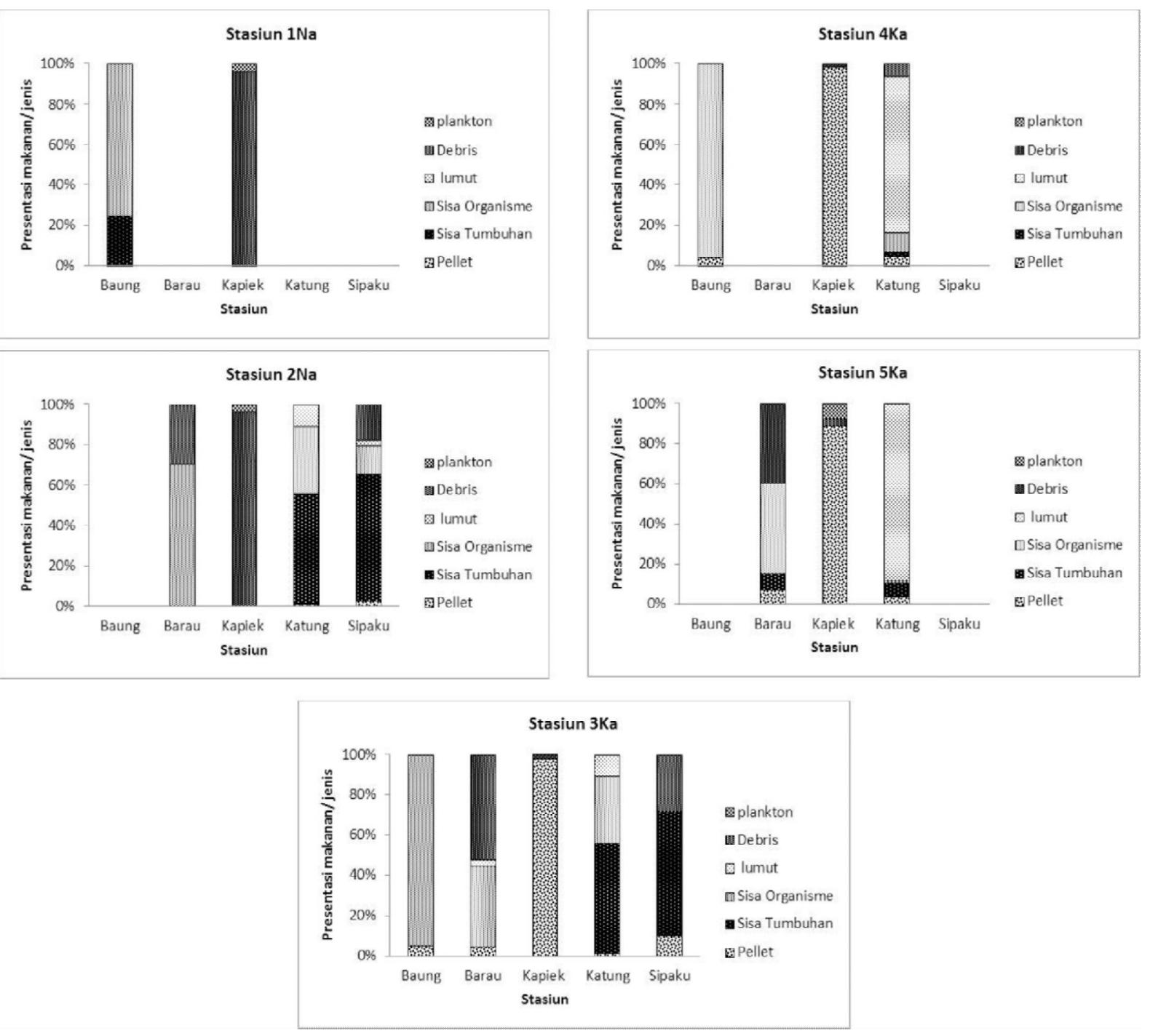

Gambar 2. Jenis makanan yang terdapat di dalam lambung ikan-ikan di lokasi penelitian 
Keterangan :

- Stasiun $1 \mathrm{Na}$ : stasiun yang berada di lokasi natural yaitu di Sungai Kampar, tidak ada karamba

- Stasiun 2Na : stasiun yang berada di lokasi natural yaitu di Waduk Koto Panjang, tetapi tidak ada karamba

- Stasiun 3Ka : stasiun yang berada di lokasi Waduk Koto Panjang, ada karamba ( 80 petak)

- Stasiun 4Ka : stasiun yang berada di lokasi Waduk Koto Panjang, ada karamba (236 petak)

- Stasiun 5Ka : stasiun yang berada di lokasi Waduk Koto Panjang, ada karamba (1266 petak)

Diantara semua jenis ikan yang tertangkap di Waduk Koto Panjang, satu-satunya ikan yang isi lambungnya didominasi oleh pelet adalah ikan kapiek (Gambar. 1). Di stasiun 3Ka, 4Ka dan 5Ka lebih dari 90 $\%$ isi lambung ikan kapiek adalah pelet. Sedangkan pada ikan lain seperti ikan katung, barau, sipaku dan baung, meskipun ikan tersebut dijumpai di sekitar karamba hanya sedikit pelet yang ada di dalam lambung ikan tersebut. Ikan tersebut masih menunjukkan preferensi terhadap makanan alami ikan-ikan tersebut, misalnya isi lambung ikan katung didominasi lumut dan tumbuhan, ikan baung isi lambungnya didominasi oleh sisa organisme, ikan sipaku isi lambungnya di dominasi oleh sisa tumbuhan dan ikan barau isi lambungnya didominasi oleh sisa organisme dan debris. Fakta ini menunjukkan bahwa meskipun ikan-ikan hidup di sekitar karamba, ikan-ikan tersebut tidak menggantungkan hidupnya terhadap sisa pelet yang tersedia di waduk Koto Panjang sebagai bahan makanan ikanikan tersebut

Hal ini berbeda dengan ikan kapiek, di mana ikan kapiek yang berada dekat karamba lambungnya penuh oleh pelet. Sedangkan ikan kapiek yang hidup di sekitar waduk Koto Panjang yang tidak ada karamba dan yang hidup di perairan sungai Kampar, isi lambungnya didominasi oleh debris. Adanya perbedaan komposisi isi lambung pada ikan kapiek ini menunjukkan pola kebiasaan makan ikan tersebut sudah berubah. Ikan kapiek sudah meninggalkan pola makan alami dan berubah memakan pelet selama ketersediaan pelet ada di perairan.Sudirmanet al(2009), menyatakan bahwa beberapa jenis ikan seperti Abudefduf vaigiensis, Plataxtaira dan Sphaeramia orbicularis yang terdapat disekitar KJA Teluk Arawange Sulawesi Selatan sudah mengalami perubahan pola makan pada ikan-ikan tersebut, dimana ikan yang berada di sekitar karamba memanfaatkan pelet yang keluar dari dalam karamba dan memanfaatkan algae yang menempel di jaring KJA. $\mathrm{Hal}$ ini mengindikasikan bahwaadanya karamba dapat mempengaruhi jenis makanan ikan yang terdapat di sekitar karamba dan merubah pola makan ikan tersebut.

Adanya sedikit pelet di dalam lambung ikan katung, barau dan baung kemungkinan hanya ikut tertelan pada saat ikan itu mengambil makanannya. Ikan katung pada stasiun $4 \mathrm{Ka}$ dan $5 \mathrm{Ka}$, tidak memanfaatkan karamba secara langsung, tapi adanya karamba merupakan media yang baik bagi perkembangan lumut, sehingga ikan memanfaatkan lumut sebagai makanannya. Ikan baung memakan berbagai jenis organisme yang ada di sekitar karamba seperti ikan kecil dan crustacea, ikan baung juga mendapatkan manfaat secara tidak langsung dari adanya karamba. Ikan barau memakan sisa organisme dan debris yang ada di sekitar karamba. Sedangkan ikan kapiek di sekitar karamba benar-benar mencari makan, karena adanya makanan yang tersedia/pelet di sekitar karamba.

\section{SIMPULAN}

1) Di area yang tidak terdapat karamba (natural) dan daerah sekitar karamba, jenis ikan yang ditemukan tidak jauh berbeda, kecuali pada Sungai Kampar jenis ikan lebih sedikit. Ikan yang terdapat di lokasi penelitian adalah sebanyak 31 jenis. Diantara ikan yang ada di sekitar karamba, ikan kapiek (Puntius schwanenfeldii), yang paling banyak ditemukan.

2) Dilihat dari komposisi isi lambung, satu-satunya ikan yang memanfaatkan sisa pelet yang keluar dari karamba adalah ikan kapiek (ikan oportunis). Ikan lain seperti barau (Hampala bimaculata), katung (Pristolepis grotii), sipaku (Cyclocheilichtys apogon) dan lain-lain pola makannya tidak beruba.

\section{DAFTAR PUSTAKA}

Affandi, R, J.S. Sjafei, M.F. Rahardjo dan Sulistiono. 2009. Fisiologi Ikan, Pencernaan dan Penyerapannya. IPB Press. 240 hal.

Chen, Y.S., M.C.M, Beveridge and T.C. Telfer. 1999. Short communication on Settling rate characteristics and nutrient content of the faeces of Atlantik salmon, Salmosalar L., and the implication for modeling of solid waste dispersion. Aquaculture research 30 p. 395-398.

Cho, C.Y. and D.P. Bureau. 2001. A review of diet formulation strategies and feeding system to reduce excretory and feed wastes in aquaculture. Aquaculture research 32 p. 349-360.

Das, C. P. S. Ayyappan and J. Jena. 2005. Comparative Changes in Water Quality and Role of Pond Soil After Application of Different Levels of Organic and in Organic Inputs. Aquaculture research 36 p. 785-798.

Effendie, M.I. 1979. Metoda Biologi Perikanan. Yayasan Dewi Sri. Bogor. 112 hal.

Fernandez-Jove, D., P. Sanchez-Jerez, J. T. Bayle-Sempere, C. Valle and T. Dempster. 2008. Seasonal patterns and diets of wild fish assemblages associated with Mediterranean coastal fisih farm. ICES Journal Marine Science, 65:1153-1160.

PT. PLN (Persero) Pembangkit Sumatera Bagian Utara Sektor Pembangkit Pekanbaru. 2012. Pemantauan Pelaksanaan Rencana Pengelolaan Lingkungan (RKL) dan Rencana Pemantauan Lingkungan (RPL) PLTA Koto Panjang Periode TriwulanIV. Pekanbaru.

Sudirman, H., H. Halide, J. Jompa, Zulfikar, Iswahyudin and A.D. McKinnon. 2009. Wild Fish associated With Tropical sea cage aquaculture in South Sulawesi, Indonesia. Aquaculture 286, 233 239.

Kottelat, M., A.J. Whitten, M.S. Kartikadan S. Wiroatmojo. 1993. Ikan air tawar di Indonesia bagian Barat dan Sulawesi. Seriplius Edition (HK), Ltd. Kerjasamadenganproyek EMDI, Kantor Menteri Negara KependudukandanLingkunganHidup R.I. Jakarta. 293 hal.

McVey, J.P. 1991. Handbook of Mariculture. Vol. II. Finfish Aquaculture.CRC Press. Boca Raton. $256 \mathrm{p}$.

Mente, E., G.J. Pierce, N. J. Spencer, J. C. Martin, I.T. Karapanagiotidis, M. B. Santos, J. Wang and C. Neofitou. 2008. Diet of Demersal Fish Species in Relation to Aquaculture Development in Scottish Sea Lochs. Aquaculture 277, 263-274.

Pillay, T.V.R. 1994. Aquaculture Development: Progress and Prospect. Fishing News Books, Osney Mead, Oxford. 182p

Sumiarsih dan Windarti, 2009.Identifikasi dan analisa isi lambung ikan-ikan yang hidup di sekitar karamba di Waduk PLTA Koto Panjang. Jurnal Perikanan dan KelautanVol 14. No 2. Hal 147-159.

Valle. C, J. T. Bayle-Sempere, T. Dempster, Sanchez-Jerez, F. GimenezCasalduero. 2007. Temporal Variability of Wild Fish Assemblages Associated With A Sea-Cage Fish Farm in The South-Western Mediterranean Sea. Estuarine, Coastal and shelf Science 72, 299 -307 . 